de propagación (esquejes, división de matas, estolones) en especies de Pteridófitas y Fanerógamas, evaluando la eficiencia de las técnicas empleadas para incorporarlas a micro-emprendimientos regionales viveristas.

\section{RESULTADOS}

Hasta el momento se han catalogado más de cincuenta especies nativas con potencial ornamental, pertenecientes a 44 géneros y 22 familias de los grupos botánicos de las Pteridófiotas y Angiospermas. En el Cuadro 1 se presentan algunas de ellas.

Con la información recabada de cada especie se confeccionó un banco de datos sobre usos y propiedades de la flora regional autóctona y se diseñaron fichas técnicas que incluyen e ilustran los aspectos relevantes de cada una de ellas. Los datos suministrados en cada ficha son: nombres vernáculos, nombre científico, familia botánica, características morfo-fisonómicas atractivas, fotografías y esquemas ilustrativos, condiciones del hábitat y requerimientos de cultivo. Publicaciones preliminares (Barrionuevo, et al. 2004) muestran que la información de las fichas técnicas son de gran utilidad para caracterizar las especies ornamentales nativas y promover su utilización.

\section{CONCLUSIONES}

La caracterización y el conocimiento integral morfo-anatómico y los métodos de multiplicación de plantas nativas con potencial ornamental, constituyen el punto de partida para su reconocimiento y valoración.

La adaptación a los sistemas de cultivo favorece la propagación y permite encarar planes de mejoramiento vegetal. La difusión de sus cualidades y la venta de las plantas evitarán la extracción de su hábitat natural y brindará una importante fuente de trabajo a viveristas y aficionados al cultivo de plantas de las localidades serranas de Córdoba.

\section{BIBLIOGRAFÍA}

BARRIONUEVO, V. 2004. Evaluación de dos especies nativas de Glandularia para su cultivo como ornamentales. II Congreso Argentino de Floricultura y Plantas Ornamentales. I.N.T.A. Buenos Aires.

CABIDO, M.; ZAK. M. 1999. Vegetación del Norte de Córdoba. IMBIV, UNC- CONICET.

ZULOAGA, F. O.; MORRONE, O 1999. Catálogo de las Plantas Vasculares de la República Argentina. III Monogr. Syst. Bot. Missouri Bot. Gard. 60: $1-323$

Agro Sur 34 (1-2):47-48 2006

\title{
GERMINACIÓN DE CINCO ESPECIES NATIVAS CON VALOR ORNAMENTAL DE LA XII REGIÓN*
}

\section{GERMINATION OF FIVE NATIVE SPECIES FROM THE XII REGION, CHILE, WITH ORNAMENTAL VALUE}

\author{
Caicheo, A.', Vera, M.', Dollenz, O.', Yagello, J.' y Massardo, F. ${ }^{3}$ \\ 'Escuela de Recursos Naturales Renovables y Acuáticos, ${ }^{2}$ Departamento de Ciencias, ${ }^{3}$ Parque \\ Etnobotánico Omora, Sede Puerto Williams, Universidad de Magallanes; Correo Puerto \\ Williams, XII Región. E-mail: francisca.massardo@umag.cl
}

\section{INTRODUCCIÓN Y OBJETIVOS}

La Región de Magallanes y Antártica Chilena alberga numerosas especies arbustivas con enorme potencial ornamental. Entre éstas, dos Berberidaceae, el calafate (Berberís buxifolia) y el michay (B. ilicifolia) son arbustos considerados ornamentales gracias a su follaje brillan- te, llamativas flores amarillas polinizadas por insectos y bayas comestibles azules a negras consumidas por aves silvestres. Una Fabaceae arbustiva, el neneo o lengua de fuego (Anarthrophyllum desideratum) exhibe una peculiar forma de crecimiento de tipo cojín propia de la zona altoandina. Su atractiva arquitectura resalta aún más con el fuerte colorido y sincronía de 
sus flores rojas. Una Asteraceae muy común, el romerillo (Chiliotrichum diffusum), destaca por su floración masiva hacia fines de la temporada reproductiva, en los meses de enero y febrero. Sus flores blancas y follaje perenne llaman la atención de la población. Una Verbenaceae característica de la Patagonia árida de Magallanes es la mata negra (Junellia tridens) que cautiva por la fragancia de sus flores, el color oscuro verde-azul y textura carnosa de su denso follaje. Por estos atributos ornamentales, estas cinco especies arbustivas forman parte de un proyecto FIA (FIA-PI-C-2002-1-A-070) destinado en la propagación de especies nativas de Magallanes con uso potencial en jardinería.

Aunque la reproducción vegetativa de individuos plus para las cinco especies mencionadas es deseable por la estabilidad genética que representa el clonamiento, es indispensable complementar tal técnica de propagación con estudios y métodos de reproducción sexual como una manera de mantener su variabilidad genética potencial en bancos de germoplasma regionales. El objetivo de este trabajo es conocer y caracterizar las semillas e investigar el comportamiento de germinación de estas cinco especies arbustivas.

\section{MATERIAL Y MÉTODO}

Para cada una de las cinco especies en estudio se colectaron aproximadamente 1000 frutos provenientes de al menos 20 individuos en dos temporadas reproductivas: entre diciembre del 2003 y marzo 2004 y entre diciembre del 2004 y marzo 2005. Las bayas de B. buxifolia y $B$. ilicifolia se colectaron en Bahía Mejillones, costa norte de la isla Navarino en la zona de transición de la Reserva de Biosfera Cabo de Hornos $\left(55^{\circ} \mathrm{S}\right)$. Las vainas de A. desideratum se colectaron en las cercanías del Parque Nacional Torres del Paine $\left(51^{\circ} 35^{\prime} \mathrm{S}\right)$. Las semillas de $C h$. diffusum y $J$. tridens se colectaron en zonas de estepa arbustiva a $120 \mathrm{~km}$ al noreste de la ciudad de Punta Arenas (52 $\left.40^{\prime} \mathrm{S}\right)$. Las semillas se limpiaron y se almacenaron a $8^{\circ} \mathrm{C}$ hasta su germinación. Se obtuvo el peso (semillas $\mathrm{g}^{-1}$ ), la viabilidad (\% TTC), \% de humedad y curva de imbibición de las semillas para cada una de las especies. La germinación natural de las semillas desinfectadas se evaluó a $22^{\circ} \mathrm{C}$ en un sistema de placas Petri con papel absorbente. En aquellos casos donde la germinabilidad fue baja, se realizaron tratamientos de escarificación, de estrati- ficación a $4 \pm 1^{\circ} \mathrm{C}$ y de aplicación de hormonas.

\section{RESULTADOS Y DISCUSIÓN}

Los resultados obtenidos a la fecha muestran germinación natural en semillas colectadas el 2005 de A. desideratum (41\%), Ch. diffusum (70\%) y J. tridens (48\%). En contraste, las dos especies de Berberís no presentaron germinación natural en ninguna de las temporadas de colecta. Los tratamientos pre-germinativos tuvieron efecto en todas las especies. La estratificación a $4^{\circ} \mathrm{C}$ en oscuridad por al menos 1500 $\mathrm{h}$ induce la germinación de Berberís buxifolia $(5 \%)$ y de B. ilicifolia (6\%). En este momento se evalúa si períodos superiores de exposición a bajas temperaturas aumenta el porcentaje de germinación de las semillas de estas dos especies de Berberís.

En las semillas colectadas en la temporada 2003-2004, la estratificación durante $1500 \mathrm{~h}$ aumentó la germinación de J. tridens. En contraste, la estratificación redujo la germinación de $A$. desideratum y de Ch. diffusum. El tratamiento de escarificación redujo a cero la germinación de $J$. tridens y Ch. diffusum, $y$ no indujo germinación en las especies de Berberis. Para la Fabacea $A$. desideratum, el tratamiento de escarificación aumentó el porcentaje de germinación que alcanzó un $80 \%$.

\section{CONCLUSIÓN}

En conclusión, tres de las especies estudiadas -A. desideratum, Ch. diffusum y J. tridens- presentan germinación natural. En cambio, las semillas de dos especies de Berberis no germinan en forma natural tanto inmediatamente después de la colecta como luego de un año de almacenamiento a $8^{\circ} \mathrm{C}$. Respecto a los tratamientos para aumentar el porcentaje de germinación, se concluye que la escarificación acida mejora la germinación del arbusto A. desideratum $y$ no afecta la germinación de los Berberis. La estratificación a $4^{\circ} \mathrm{C}$ es indispensable para la germinación de ambas especies de Berberis y mejora la germinación de $J$. tridens. En cambio, la estratificación está contraindicada para $C h$. diffusum $y$ A. desideratum puesto que reduce los porcentajes de germinación de sus semillas.*

* Trabajo financiado por el Proyecto FIA-PI-C-2002-1-A-070. 